\title{
Studying the Effects of Autoclaving Process on Orthodontic Archwires
}

\author{
Valeri Petrov ${ }^{1}$, Ivana llievska ${ }^{2}$, Laura Andreeva ${ }^{1}$, Valdek \\ Mikli $^{3}$, Andrzej Zaleski ${ }^{4}$, Angelina Stoyanova-Ivanova ${ }^{2}$
}

1. Faculty of Dental Medicine, Medical University Sofia,St. Georgi Sofiiski Blvd., 1431 Sofia, Bulgaria;

2. Institute of Solid State Physics, BAS, 72 Tzarigradsko Chaussee Blvd., 1784 Sofia,Bulgaria;

3. Centre for Materials Research, Tallinn University of Technology, Ehitajate 5, Tallinn 19086, Estonia;

4. Institute of Low Temperature and Structure Research, Polish Academy of Sciences, ul. Okolna 2, 50-422 Wroclaw, Poland

\begin{abstract}
In the orthodontic practice during treatment with fixed appliances, different types of wires made of different metal alloys, by different manufacturers are used. However, there is lack of precise information about their composition, structure and optimal length of stay in the patient's mouth. This information is important because it helps orthodontists to choose the appropriate archwire for the proper stage of orthodontic treatment. The most commonly used ones are the following types of orthodontic wires: stainless steel, nickel-titanium, titanium-molybdenum and heat- activated. Medical standards for the prevention and control of nosocomial infections aim to improve the quality and safety of medical care by reducing the incidence of nosocomial infections and by limiting the spread of
\end{abstract}


antimicrobial resistance. In this regard, it is important to know whether autoclaving may be carried out in all types of orthodontic wires and to ensure that the autoclaving process does not affect the chemical composition and surface structure of the archwires. The aim of this work is to investigate the effect of the process of autoclaving stainless steel, nickel-titanium, titanium molybdenum, heat-activated nickel titanium and copper-nickel-titanium orthodontic archwires with the same dimension and size of $0.016 \times 0.022$ inches. The analysis was carried out via the following independent techniques: X-ray diffraction analysis (XRD), Scanning Electronic Microscopy (SEM), Energy Dispersive Spectroscopy (EDX) and Differential Scanning Calorimetry (DSC).It has been established that the autoclaving process does not affect the chemical composition and surface structure of the archwires and does not lead to the deterioration of their properties.

\section{Keywords: autoclaving process, orthodontic archwires, XRD, SEM, DSC}

\section{Introduction}

In the orthodontic practice during treatment with fixed appliances different types of wires made of different metal alloys, by different manufacturers are used. Unfortunately, the perfect archwires, which are suitable for each stage of the treatment, have not been created yet. Therefore, orthodontic wires of different alloys with different characteristics, meeting the requirements of the specific stage are manufactured. The most commonly used types of orthodontic wires are as follows: stainless steel, nickel-titanium, titaniummolybdenum and heat- activated. The stainless steel (1) wires possess a relatively high elastic modulus, but have an excellent molding, suitable bouncing and are characterized to possess a low frictional resistance. Moreover, they can be welded, have a good resistance to corrosion and come at a moderate price. The steel archwires are appropriate during all of the treatment stages with fixed appliances, except for the initial stage in which the first archwire used should be very elastic. Nickel-titanium archwires $(2,3)$ exert the lightest force and have the biggest elastic range compared to stainless steel and titaniummolybdenum alloys. Furthermore, they have a distinctive bouncing property, which is especially pronounced in the ones with shape memory. However, these archwires mold poorly and certain elements cannot be welded at all. Nickel-titanium alloys have two forms of crystal lattice: martensitic and austenitic. Wires in the martensitic state are classified as non-superelastic, however the austenitic ones are defined as super-elastic. Beta-titanium alloy has been used for the making of orthodontic archwires by Burstone and Goldberg (4). When activated these wires exert a weaker impact compared to those made of stainless steel and cobalt-chromium-nickel alloys. They also have an excellent morphology and allow the welding of additional elements. Beta-titanium archwires are the most expensive orthodontic alloys, but orthodontists believe that the higher price can be compensated by the the fact that they require to be changed much less often. In 1994 orthodontic archwires of a new kind of alloy were manufactured, which resulted in three variants of temperature-dependent orthodontic wires. They were called heat-activated, because their characteristics change at elevated temperatures by passing from a martensitic to an austenitic state, thus restoring their original form. Kusy (5) reported that these archwires, except nickel and titanium, contain a minimum 5 to $6 \%$ by weight copper and 0.2 to $0.5 \%$ by weight chromium. Copper-nickel-titanium archwires are very useful for pain-sensitive patients. They are much more elastic at room temperature and 
can be placed easily in the slot of the bracket, even in very crowded teeth. Heat-activated archwires are ideal for leveling during the first phase of treatment with fixed appliances.

Medical standards for the prevention and control of nosocomial infections aim to improve the quality and safety of medical care by reducing the incidence of nosocomial infections and by limiting the spread of antimicrobial resistance. In this regard it is important to know whether autoclaving may be carried out in all types of orthodontic wires and to ensure that the autoclaving process does not affect the chemical composition and surface structure of the archwires.

\section{Objective I Aim:}

The aim of this work is to investigate the effect of the process of autoclaving, as a method of sterilization and disinfection of metal orthodontic materials, the chemical composition and surface structure of the main types of orthodontic archwires, proposed and used for treatment in Bulgaria.

\section{Material and Methods:}

The main types of archwires subject to this study were as follows: stainless steel, nickel-titanium, titanium molybdenum, heat-activated - nickel-titanium and copper-nickel-titanium, with the same dimension and size of $0.016 \times 0.022$ inches. Eight orthodontic archwire pieces produced by the same manufacturer were examined -4 as-received and 4 as-received autoclaved (Table 1). For each study five areas of the orthodontic archwires were selected (one from the frontal area, two canine teeth-sided area bilaterally and two from the end of the archwire - both sides). There were a total of 40 areas of archwire relevant analyses conducted.

Table 1. Type and category of investigated archwires

\begin{tabular}{|l|l|l|}
\hline Type of archwires & Dimension[inches] & Category \\
\hline A-stainless-steel (SS) & $0.016 \times 0.022$ & A0 - as-received \\
\cline { 3 - 3 } & & A1 - as-received autoclaved \\
\hline B- nickel-titanium (Ni-Ti) & $0.016 \times 0.022$ & B0 - as-received \\
\cline { 3 - 3 } & & B1 - as-received autoclaved \\
\hline C- titanium molybdenum (TMA) & $0.016 \times 0.022$ & C0 - as-received \\
\cline { 3 - 3 } & & C1 - as-received autoclaved \\
\hline $\begin{array}{l}\text { D1 - heat-activated } \\
\text { nickel-titanium (Ni-Ti) }\end{array}$ & $0.016 \times 0.022$ & D10 - as-received \\
\cline { 3 - 3 } $\begin{array}{l}\text { D2 - heat-activated } \\
\text { copper- nickel-titanium (Cu-Ni-Ti) }\end{array}$ & $0.016 \times 0.022$ & D11 - as-received autoclaved \\
\cline { 3 - 3 } & & D20 - as-received \\
\hline
\end{tabular}


The analyses were carried out via these independent techniques: X-ray diffraction analysis (XRD), Scanning Electronic Microscopy (SEM), Energy Dispersive Spectroscopy (EDX) and Differential Scanning Calorimetry (DSC).

\section{Results and discussion:}

\section{A -Stainless Steel (SS)}

Usually from the information brochure which the manufacturers provide, it is not clear what is the exact composition of the produced SS orthodontic materials and the way in which the alloys have been treated (6). Therefore, in order to investigate the chemical composition of the SS orthodontic archwires before and after autoclaving, we made an EDX analysis (7) (Table 2).

Table 2: Average element content of investigated SS archwies.

\begin{tabular}{|l|l|l|l|l|l|l|}
\hline Elements & $\begin{array}{l}\mathrm{Si} \\
(\mathrm{wt} \%)\end{array}$ & $\begin{array}{l}\mathrm{Cr} \\
(\mathrm{wt} \%)\end{array}$ & $\begin{array}{l}\mathrm{Mn} \\
(\mathrm{wt} \%)\end{array}$ & $\begin{array}{l}\mathrm{Fe} \\
(\mathrm{wt} \%)\end{array}$ & $\begin{array}{l}\mathrm{Ni} \\
(\mathrm{wt} \%)\end{array}$ & Total \\
\cline { 1 - 7 } Type of investigated archwires & $-1 \%$ & $18 \sim 20 \%$ & $-2 \%$ & $-71 \%$ & $8 \sim 11 \%$ & \\
\hline Literature data (2) & $0.82 \%$ & $19.76 \%$ & $1.54 \%$ & $69.08 \%$ & $8.80 \%$ & $100 \%$ \\
\hline A0 & $0.82 \%$ & $19.70 \%$ & $1.44 \%$ & $69.67 \%$ & $8.38 \%$ & $100 \%$ \\
\hline Differences & $0 \%$ & $-0.06 \%$ & $-0.10 \%$ & $0.59 \%$ & $-0.42 \%$ & \\
\hline
\end{tabular}

A statistical significant difference is not present in the study of the chemical composition of as-received and as-received autoclaved SS archwires. The indicated change in the quantity of iron is at a higher average value of $0.59 \mathrm{wt} \%$ and at a lower average value in the amount of nickel of $0.42 \mathrm{wt} \%$ and would not affect the surface properties of the material. Figure 1 illustrates surface microstructure images of asreceived and as-received autoclaved SS archwires.
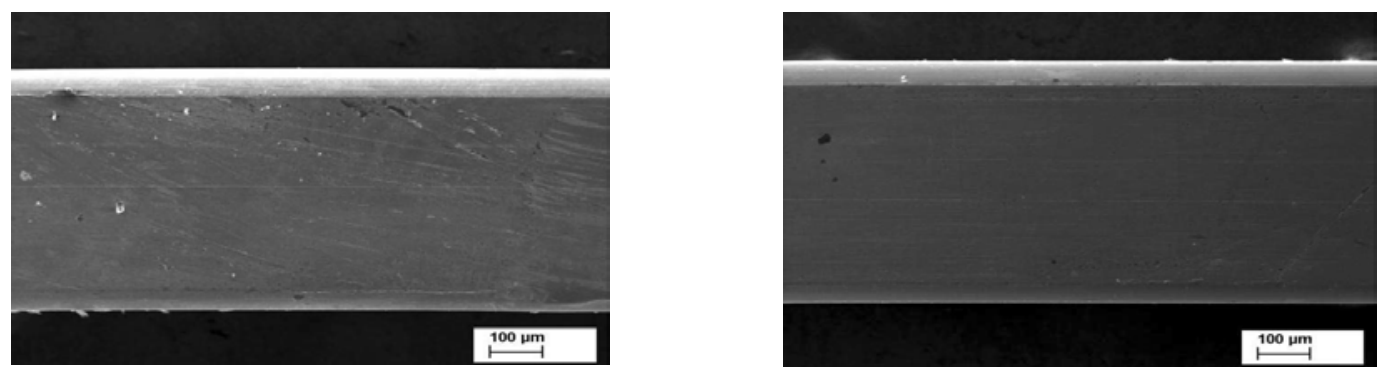

Figure 1.SEM images of as-received (A) and as-received autoclaved (B) SS archwires. 
SEM analysis does not establish any changes in the surface structure of the investigated archwires and no corrosion processes or increase of roughness has been observed. The authors (2) established that in as-received SS archwires only a single-phase austenitic structure is evident.

\section{B - Nickel-Titanium (Ni-Ti)}

Orthodontic archwires made from nickel-titanium alloy ( $\mathrm{Ni}-\mathrm{Ti}$ ) contain almost equal parts nickel and titanium, $54-55 \%$ nickel and $43-44 \%$ titanium, respectively, with only a minimal quantity of cobalt up to $3 \%$ $(2,8)$. The data obtained by the EDX analysis $(7)$ of the elements content in the investigated nickeltitanium orthodontic archwires before and after autoclaving are shown in Table 3.

Table 3: Average element content of the investigated $\mathrm{Ni}$-Ti archwires.

\begin{tabular}{|l|l|l|l|}
\hline Elements & $\begin{array}{l}\mathrm{Ti} \\
(\mathrm{wt} \%)\end{array}$ & $\begin{array}{l}\mathrm{Ni} \\
(\mathrm{wt} \%)\end{array}$ & Total \\
\cline { 1 - 4 } Type of investigated archwires & $\sim 54-55 \%$ & $\sim 43-44 \%$ & \\
\hline Literature data (2) & $54.56 \%$ & $45.44 \%$ & $100 \%$ \\
\hline B0 & $54.73 \%$ & $45.27 \%$ & $100 \%$ \\
\hline B1 & $0.17 \%$ & $-0.17 \%$ & \\
\hline Differences &
\end{tabular}

Figure 2 illustrates the surface structure of Ni-Ti archwires.
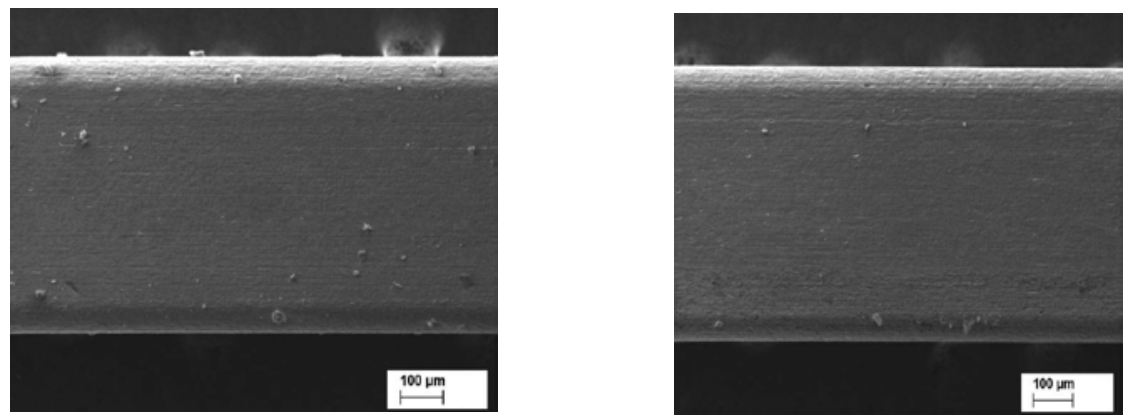

Figure 2.SEM images of as-received (A) and as-received autoclaved (B) Ni-Ti archwires.

In the investigated $\mathrm{Ni}-\mathrm{TI}$ archwires the titanium content increased by $+0.17 \mathrm{wt} \%$ and the nickel content decreased by $-0.17 \mathrm{wt} \%$, which we suppose is a result of a method error, thus showing no significant differences in the chemical composition. The SEM analysis concluded that the autoclaving process does not lead to any surface changes of the investigated archwires. 


\section{C - Titanium molybdenum (TMA)}

In the provided literature, the elements of TMA alloy are: $80 \%$ titanium, $11.5 \%$ molybdenum, $6 \%$ zirconium, and $4.5 \%$ tin $(2,8)$. Table 4 shows the EDX analysis results of the chemical composition of the surface of the investigated as-received and as-received autoclaved beta-titanium archwires (7). Observed were unremarkable changes in the chemical composition of $+0.10 \mathrm{wt} \%$ to $-0.15 \mathrm{wt} \%$, which is within the allowed method error.

Table 4: Average element content of investigated TMA archwires.

\begin{tabular}{|c|c|c|c|c|c|}
\hline Elements & \multirow{2}{*}{$\begin{array}{l}\mathrm{Ti} \\
\text { (wt\%) }\end{array}$} & \multirow{2}{*}{$\begin{array}{l}\mathrm{Zn} \\
\text { (wt\%) }\end{array}$} & \multirow{2}{*}{$\begin{array}{l}\text { Mo } \\
\text { (wt\%) }\end{array}$} & \multirow{2}{*}{$\begin{array}{l}\text { Sn } \\
\text { (wt\%) }\end{array}$} & \multirow[t]{2}{*}{ Total } \\
\hline Type of investigated archwires & & & & & \\
\hline Literature data (2) & $\sim 79 \%$ & $-6 \%$ & $-11 \%$ & $-4 \%$ & \\
\hline $\mathrm{CO}$ & $76.80 \%$ & $6.74 \%$ & $11.75 \%$ & $4.71 \%$ & $100 \%$ \\
\hline C1 & $76.84 \%$ & $6.59 \%$ & $11.75 \%$ & $4.81 \%$ & $100 \%$ \\
\hline Differences & $0.04 \%$ & $-0.15 \%$ & $0.00 \%$ & $0.10 \%$ & \\
\hline
\end{tabular}

The conducted analysis of the surface of the archwires via SEM are shown on Figure 3. From the SEM images it can be observed that there are no signs of corrosion.
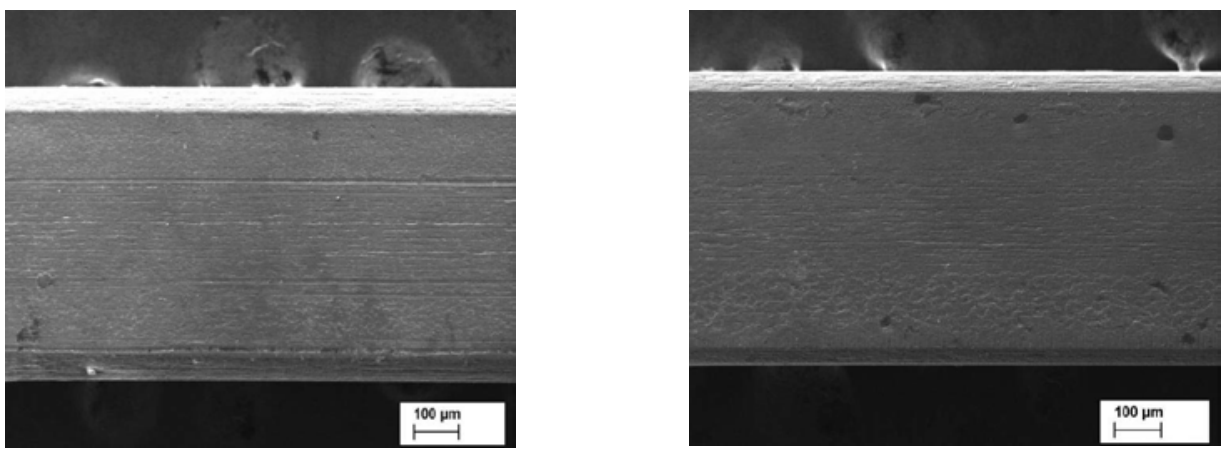

Figure 3.SEM images of as-received (A) and as-received autoclaved (B) TMA archwires.

Heat-activated orthodontic archwires are one of the most frequently used types in the initial stages of orthodontic treatment. They can release a weak and continuing force that aids the biological movement of the teeth. They possess super-elastic and thermosetting characteristics and a shape memory property. By bending and repeated temperature cycling, the orthodontic archwire in the austenitic phase is able to "remember" the pre-formed shape including the specific orthodontic shape of the dental archwire. By decreasing the temperature of the alloy, the archwire is converted into a martensitic state and becomes flexible and easily deformable and when the temperature increases, the austenitic transformation stage occurs $(9,10,11)$. The transition temperature and its alteration is particularly important, since it indicates the temperature through which the material will return entirely to the original shape and consequently 
acquire greater rigidity (12). Some of the most commonly used heat-activated archwires in our country: Ni$\mathrm{Ti}$ (D1) and Cu-Ni-Ti (D2), have been studied in this paper.

\section{D1 -Nickel-Titanium (Ni-Ti)}

Heat-activated nickel-titanium orthodontic archwires are studied by llievska et all (13). It is shown that due to the autoclaving process there are no noticeable changes of their surface, chemical composition does not change and the $\mathrm{Ni}-\mathrm{Ti}$ alloy is with an austenite type structure in room temperature. From the DSC analysis made using temperature ranges from $-50^{\circ} \mathrm{C}$ to $+50^{\circ} \mathrm{C}$ and back to $-50^{\circ} \mathrm{C}$, it can be observed that there is a transition from austenite to R-phase, without the presence of a martensitic phase. For the asreceived sterilized $\mathrm{Ni}-\mathrm{Ti}$ archwire, in the cooling process there are two peaks which are attributed to an austenite to R-phase followed by an R-phase to martensitic transition.

\section{D2 - Copper-Nickel-Titanium (Cu-Ni-Ti)}

EDX analysis was conducted on Cu-Ni-Ti (Table 5) in order to study the chemical composition and for the surface microstructure an SEM analysis was used (Figure 4).

Table 5: Average element content of investigated $\mathrm{Cu}-\mathrm{Ni}-\mathrm{Ti}$ archwires.

\begin{tabular}{|c|c|c|c|c|}
\hline Elements & \multirow[t]{2}{*}{$\overline{\mathrm{Ti}}(\mathrm{wt} \%)$} & \multirow[t]{2}{*}{$\mathrm{Ni}(\mathrm{wt} \%)$} & \multirow{2}{*}{$\begin{array}{l}\mathrm{Cu} \\
\text { (wt\%) }\end{array}$} & \multirow[t]{2}{*}{ Total } \\
\hline Type of investigated archwires & & & & \\
\hline Literature data (2) & $\sim 43 \%$ & $-50 \%$ & $\sim 6.5 \%$ & \\
\hline D20 & $46,69 \%$ & $47,15 \%$ & $6,15 \%$ & $100 \%$ \\
\hline D21 & $45,23 \%$ & $48,61 \%$ & $6,16 \%$ & $100 \%$ \\
\hline Differences & $-1,46 \%$ & $1,46 \%$ & $0.01 \%$ & \\
\hline
\end{tabular}
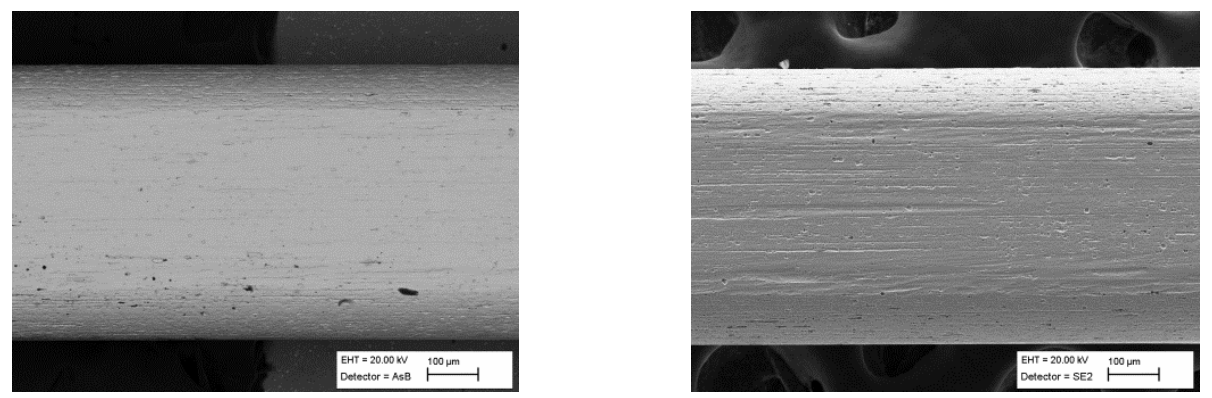

Figure 4.SEM images of as-received (A) and as-received autoclaved (B) TMA archwires

The minimal differences, as a result of the analyses, could be due to the following reasons: the analyses were made on different parts of the archwires, the alloy is not completely homogeneous, or it falls within the allowed method error. The general determination is that there is no big difference in the elemental percentage of alloy between as-received and as-received autoclaved $\mathrm{Cu}-\mathrm{Ni}$-Ti archwires. 
Figure 5 illustrates the XRD analysis of heat-activated as-received and as-received autoclaved $\mathrm{Cu}-\mathrm{Ni}-\mathrm{Ti}$ archwires and it can be seen that there is a presence of amortization and that the archwires are of an austenite type structure under room temperature.

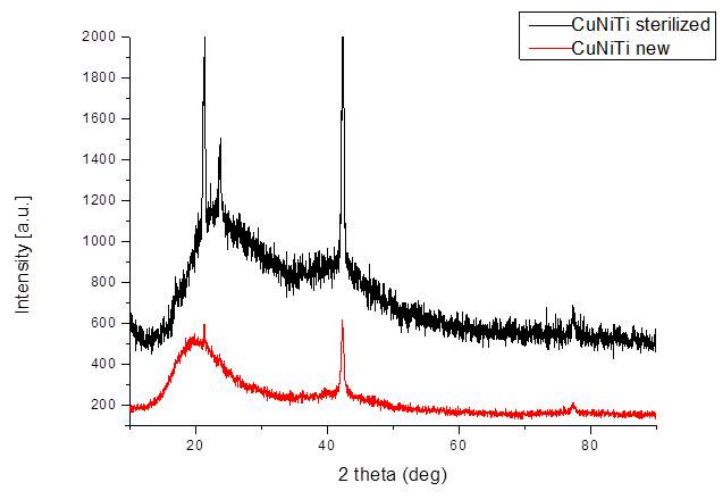

Figure 5.XRD patterns of as-received and as-received autoclaved $\mathrm{Cu}-\mathrm{Ni}-\mathrm{Ti}$ archwires.

From the DSC analysis made on Cu-Ni-Ti archwires (Figure 6), during the cooling process we observe no remarkable temperature changes between the as-received and as-received autoclaved. During the heating process it can be seen that the transition temperature changes, which can be due to surficial interaction with contamination, thus repeated measurements are going to be conducted.

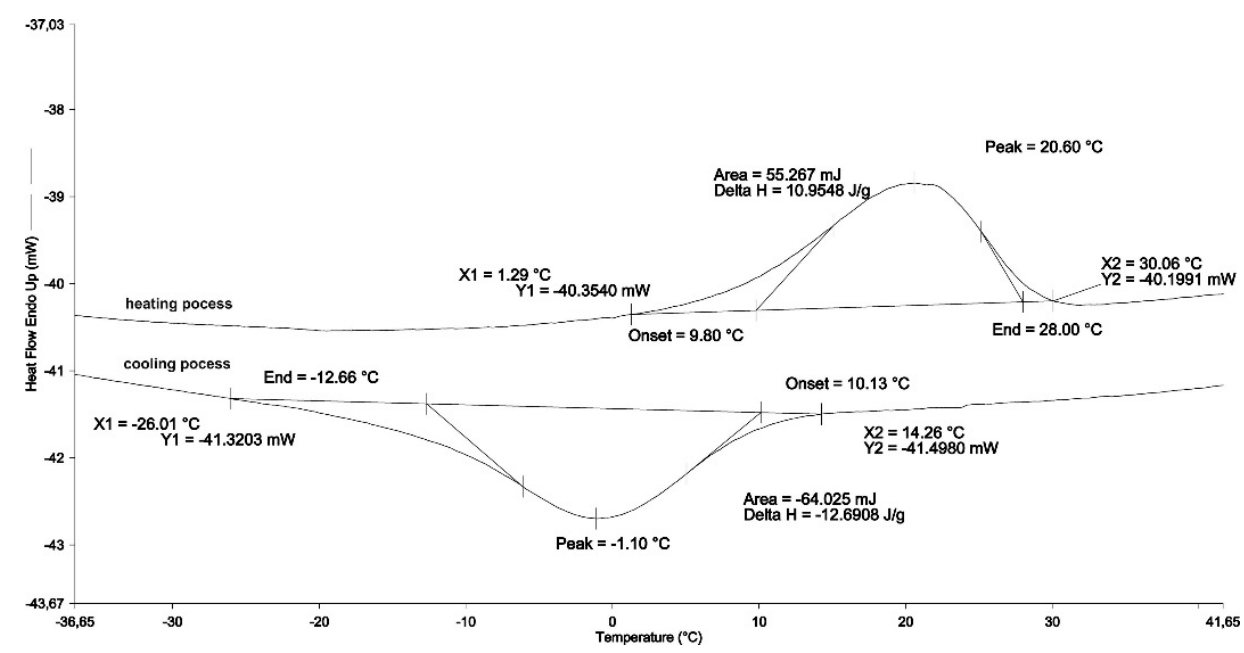




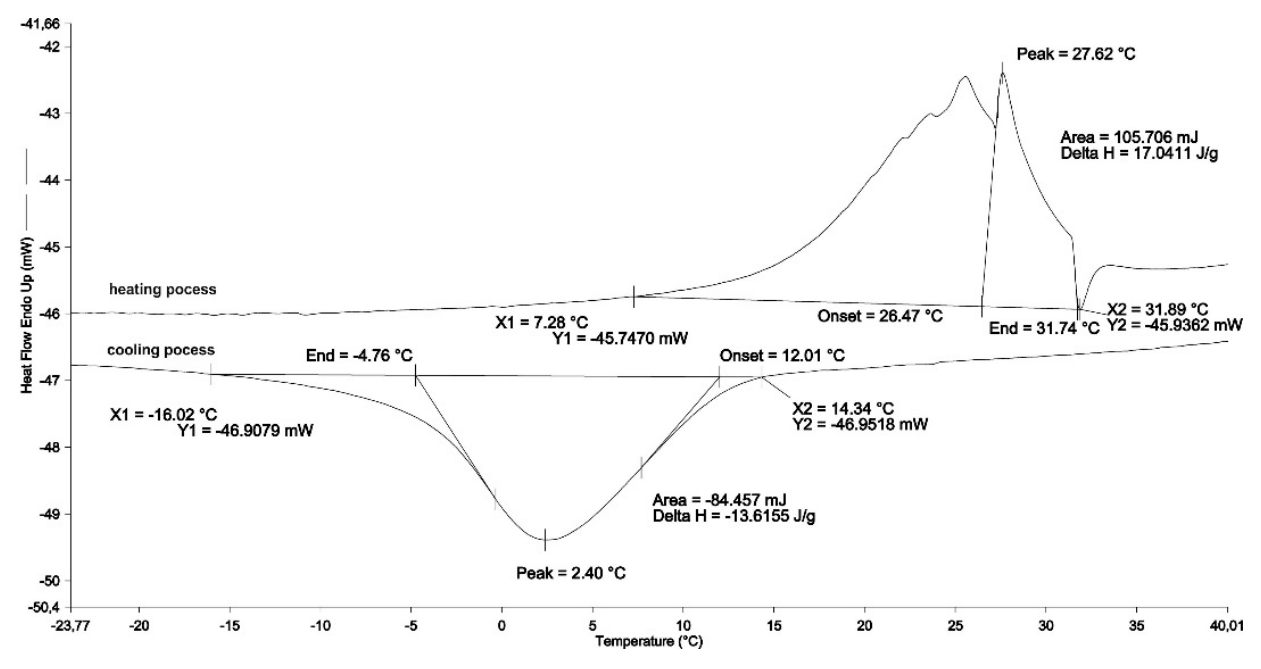

Figure 6.DSC curves of as-received (A) and as-received autoclaved (B) Cu-Ni-Ti archwire.

\section{Conclusion}

Sterilization as a method for disinfection of the orthodontic archwires before placing them in the oral cavity of the patients is useful and it helps to achieve maximal safety for the professional demands of orthodontics.

Studying of the autoclaving effect of SS, Ni-Ti, TMA, heat-activated $\mathrm{Ni}-\mathrm{Ti}$ and $\mathrm{Cu}-\mathrm{Ni}$-Ti (as-received and as-received autoclaved) orthodontic archwires, shows that there are no remarkable changes in the chemical composition and surface structure.

Heat-activated $\mathrm{Ni}$-Ti и $\mathrm{Cu}-\mathrm{Ni}$-Ti orthodontic archwires do not change their austenite type structure under room temperature.

For the as-received and as-received autoclaved Cu-Ni-Ti on DSC analyses, in the cooling process, the transition temperatures do not change.

\section{Acknoeledgments}

This work was a part of an inter-academic collaboration project between the Bulgarian Academy of Sciences, Estonian Academy of Science, Tallinn University of Technology and Institute of Low Temperature and Structure Research, Polish Academy of Sciences.

\section{References}

1. Biasi RS, Ruela ACO, Elias CN, Chevitarese O. The influence of heat treatment in orthodontic arches made of stainless steel wires. Mater Res 2000,3:97-98.

2. Brantley W, Eliades T, Orthodontic Materials. Thieme, Stuttgart. New York 2001;78-103.

3. Eliades T, Eliades G, Athanasiou A, Bradley T. Surface characterization of retrieved NiTi orthodontic archwires. Eur J Orthod 2000; 22: 317-326. 
4. Burstone CJ, Goldberg AJ. Beta titanium: a new orthodontic alloy. Am J Orthod 1980; 77: 121132.

5. Kusy RP. A review of contemporary archwires: their properties and characteristics. Angle Orthod 1997; 67: 197-208.

6. Mendes K, Rossouw PE. Friction: validation of manufacturer's claim. Semin Orthod 2003; 9: 236250.

7. Petrov V. Investigation of the chemical composition and structure of orthodontic archwires before and after treatment. PhD Thesis. Sofia 2014

8. Proffit WR: Contemporary Orthodontics, Ed.4, Mosby-Elsevier Inc., St. Louis, USA: 2007, 359394.

9. Топалски, С. "Мартензитно превръщане при деформация на монокристал от Cu-Al-Ni сплав с памет на формата.” Научни трудове на Русенския Университет 2008‘ 47, 2.

10. Funakubo H. Shape memory alloys. Precision machinery and robotic series. New York: Gordon and Breach Science; 1987.

11. Wang Q.Y., Zheng Y.F., Liu Y. Microstructure, martensitic transformation and superelasticity of Ti 49.6 Ni 45.1 Cu 5 Cr 0.3 shape memory alloy. Materials Letters 2011; 65: 74-77.

12. T. Sobottka, F. P. Valarelli, R. H. Cancado, K. M. S.Freitas, D. J. Villarinho, J App. Oral Sci., 2014; 22 109- 117.

13. Ilievska I. Petrov V. Andreeva L. Kovacheva D. Zaleski A. Drozd M. Bukowska E. Mikli V. Stoyanova-Ivanova A. Structural and morphological characterization of heat-activated, nickeltitanium archwires, Bulgarian Chemical Communications, 2017; 49, Special Issue A, 33-

\section{Corresponding author:}

Dr. Valeri Petrov

e-mail: vpetrov6@hotmail

Angelina Stoyanova-Ivanova

aksi_bg@abv.bg 